\title{
Em Tempos de Democratizaçáo do Direito à Educaçáo: como têm se Delineado as Políticas de Acesso à EJA aos Estudantes com DeficiênCia no Rio Grande do Sul? ${ }^{1}$
}

\author{
In TIMES OF DEMOCRATIZATION OF THE RIGHT TO EDUCATION: HOW HAS ACCESS \\ Policies to Youth and Adult EDUCation BeEn Outlined for Students \\ WITH DISABILITIES IN RIO GRANDE DO SUL?
}

\author{
Clarissa HAAS $^{2}$ \\ Taísa Grasiela Gomes Liduenha GONÇALVES³
}

\begin{abstract}
RESUMO: o estudo abordou as políticas públicas de acesso dos jovens e adultos com deficiência à escolarização por meio da modalidade da Educação de Jovens e Adultos (EJA), analisando sua oferta no estado do Rio Grande do Sul, em classes comuns e especiais, e cotejando-a com os indicadores estatísticos em âmbito nacional. Também foi analisada sua distribuição entre as instâncias administrativas (pública e privada) e entre as categorias privadas (filantrópica, comunitária, confessional e particular), como forma de compreender a relação público/privado na implementação das políticas de acesso à educação para esses sujeitos, no RS. As questóes consideradas relevantes a essa análise foram construídas por meio do olhar articulado aos indicadores sociais, obtidos a partir dos microdados fornecidos pelos bancos de dados do Censo Escolar da Educaçáo Básica (2007 a 2013) e do Censo Demográfico Brasileiro (2010). Constatou-se que a concentração das matrículas escolares desses sujeitos ocorre no atendimento substitutivo, por meio das classes especiais de EJA sendo muito intensa a atuaçáo das instituiçóes filantrópicas no estado. Desse modo, é possível inferir que, com relação aos tempos de vida jovem e adulto, as açóes políticas intergovernamentais de Educação Especial em foco estấo em descompasso em relação à tendência de intensificação da diretriz da inclusão escolar expressa no cômputo das matrículas gerais da Educação Básica, em ambos os contextos. Além disso, a garantia do direito à educação do jovem e adulto com deficiência persiste como aspecto marginal no estado do Rio Grande do Sul e no Brasil.
\end{abstract}

PALAVRAS-CHAVE: Educação Especial. Educação de Jovens e Adultos. Indicadores Sociais. Políticas Públicas.

\begin{abstract}
The study was on public policies for access of youth and adult people with disabilities through the modality of Youth and Adults Education (EJA, in Portuguese), analyzing their supply in Rio Grande do Sul state, in regular and special classes, and comparing it with nationwide statistical indicators. Its distribution between administrative institutions (public and private) and between private categories (philanthropic, community, confessional and particular) was also analyzed as a way to understand the public/private relationship in the implementation of educational access policies for these individuals in RS. The issues considered relevant to this analysis were built through an articulated view towards the social indicators obtained through the microdata provided by Basic Education Census (2007-2013) and the Brazilian Census (2010) databases. It was found that the concentration of enrollment of these individuals occurs in substitute service, through EJA special classes, which presents very intense performance by philanthropic institutions in the state. Thus, we can infer that, with respect to young and adult lifetimes, intergovernmental political actions of Special Education in focus are in imbalance with the intensifying trend of school inclusion policy expressed in the total numbers of general enrollment Basic Education, in both contexts. In addition, the guarantee of the right education of youth and adults with disabilities remains a marginal aspect in Rio Grande do Sul state and in Brazil.
\end{abstract}

KEYWORDS: Special Education. Youth and Adult Education. Social Indicators. Public Policies.

\footnotetext{
${ }^{1}$ http://dx.doi.org/10.1590/S1413-65382115000400009

${ }^{2}$ Doutoranda em Educação do Programa de Pós-Graduação em Educação da Universidade Federal do Rio Grande do Sul. Porto Alegre, RS, Brasil. cla.haas@hotmail.com

${ }^{3}$ Docente do Programa de Mestrado em Metodologias para o Ensino de Linguagens e suas Tecnologias na Universidade Norte do Paraná (UNOPAR). Estágio de Pós-Doutoramento pela UEL. Londrina, PR, Brasil. taisaliduenha@gmail.com
} 


\section{INTRODUÇÃo}

Em tempos de democratização do direito à educação, sua garantia está amplamente prevista nos preceitos legais e normativos de nosso país. Desde 2009, com a Emenda Constitucional n. 59/2009 (BRASIL, 2009a), a extensão daobrigatoriedade do direito à educação ampliou-se às faixas etárias de quatro a 17 anos de idade. A escola pública brasileira passou a viver o desafio de incluir os estudantes em idade escolar, sem desconsiderar os que estão fora da faixanomeada como "idade própria”, por força da lei. Interessa-nos, neste estudo, problematizar a garantia do direito à educação àqueles que estão fora da "idade própria" (a partir dos 17 anos) elou, ainda, àqueles que, nos dois últimos anos de idade escolar obrigatória (a partir dos 15 anos), ingressam na modalidade da Educação de Jovens e Adultos (EJA) - Etapa Fundamental, construindo um percurso escolar paralelo àquele tratado como ensino regular. Associamos a essas trajetórias na EJA a condição do alunado como público-alvo da Educação Especial $^{4}$, focando nossa análise naqueles que, historicamente, foram duplamente marginalizados pela escola: pela condição da deficiência e pela idade escolar avançada.

Portanto, o presente texto discute as políticas públicas de acesso dos jovens e adultos com deficiência à escolarização por meio da modalidade da Educação de Jovens e Adultos (EJA), nas classes comuns e especiais, nas escolas do estado do Rio Grande do Sul (RS).

Ao nos debruçarmos sobre a análise das políticas públicas que contemplam os sujeitos da educação especial na EJA, em um dos 27 estadosfederados (RS) que compóem a República Federativa Brasileira, entendemos necessário o destaque à importância da intensificação dos direcionamentos legais e normativos a favor de uma política nacional de Educação Especial na perspectiva da Educação Inclusiva, nas últimas décadas, no país. Esse posicionamento pode ser retomado em estudos anteriores, tais como os de Baptista (2011) e de Baptista, Haas e Freitas (2014).

Baptista, Haas e Freitas (2014) refletem acerca do fortalecimento da diretriz da inclusão escolar no Brasil e no estado do RS, por meio do cômputo geral das estatísticas educacionais dos sujeitos públicos-alvo da Educação Especial na Educação Básica, demonstrando a ampliação progressiva das matrículas no ensino comum no espaçotemporal de 2008 a 2013 em ambos os contextos. Citam o ano de 2008 como um marco histórico, pois, nesse ano, ocorreua publicação do Documento Orientador da Política de Educação Especial na perspectiva da Educação Inclusiva (BRASIL, 2008a), bem como a inversão na tendência histórica das matrículas dos sujeitos da educação especial nos espaços de atendimento escolar exclusivos da Educação Especial que, em termos percentuais ou números absolutos, passou a ser maior nas classes de ensino comum.

Ao lançarmos nosso olhar aos tempos de vida do jovem e adulto com deficiência aqueles aos quais se associam comumente as histórias de fracasso escolar -, entendemos que se tornam relevantes as seguintes questóes: as políticas públicas de acesso do jovem e adulto com deficiência à escolarização acompanham as tendências dos indicadores estatísticos da totalidade

\footnotetext{
${ }^{4}$ São públicos-alvo da Educação Especial os estudantes com deficiência, transtornos globais do desenvolvimento e altas habilidades ou superdotação (BRASIL, 2008a). Ao longo do texto, utilizaremos as expressôes "alunos com deficiência" de maneira abrangente, referindo-nos a todos os sujeitos que são públicos-alvo da Educação Especial, por ser essa a caracterização predominante entre os sujeitos. Também utilizaremos a expressão Necessidades Educativas Especiais (NEE) para nos referirmos às categorias de análise dos dados estatísticos do Censo Escolar da Educação Básica, uma vez que é essa a nomenclatura utilizada pelo Censo, em alusão ao público-alvo.
} 
da Educação Básica, no que concerne à intensificação da diretriz de inclusão escolar? Quais são os bancos escolares da EJA ocupados pelos jovens e adultos com deficiência no estado do RS? São predominantemente os bancos das classes especiais ou das classes comuns de EJA? São os bancos escolares das escolas públicas ou privadas (particulares, comunitárias confessionais e filantrópicas)? Que leituras são possíveis das matrículas de acesso à EJA comum e especial, tomando como aspectos de atenção as tipologias de deficiência?

Essas questóes assumem ainda mais importância quando se considera como aspecto de análise a (pouca) atenção dada pelos documentos normativos da Política Nacional de Educação Especial na perspectiva da Educação Inclusiva a esta faixa etária. Haas (2013) aborda a (in) visibilidade dos jovens e adultos com deficiência nos documentos normativos da Política de Educação Especial na perspectiva da Educação Inclusiva. Conforme a autora,há menção explícita, nos instrumentos da política, a esses tempos de vida apenas em um parágrafo do Documento Orientador da Política Nacional de Educação Especial na perspectiva da Educação Inclusiva (BRASIL, 2008a):

Na modalidade da Educação de Adultos e Educação Profissional, as açôes da Educaçáo Especial possibilitam a formaçáo das oportunidades de escolarizaçáo, formação para ingresso no mundo do trabalho e efetiva participação social (BRASIL, 2008a, p.22).

Buscamos cotejar os dados estatísticos obtidos no cenário estadual (RS) com os indicadores nacionais, como forma de averiguar as sintonias e dissonâncias entre as políticas públicas de educação especial na perspectiva da educação inclusiva em implementação em ambos os contextos. No momento histórico atual, a política educacional brasileira tem como agenda prioritária a implementação do Plano Nacional de Educação (PNE 2014-2024), expresso na Lei Federal 13.005/2014 (BRASIL, 2014a), e a recomendação legal de que esse planejamento nacional para a década seja capaz de articular a efetivação do Sistema Nacional de Educação ${ }^{5}$,enquanto um conjunto articulado e coordenado de elementos coexistentes, que, dentro de um determinado espaço e tempo, compartilhe de um mesmo ordenamento estruturado, com vistas, sobretudo, à garantia da universalização da educação básica obrigatória dos quatro aos 17 anos, em regime de colaboração entre os entes federados (união, estados e municípios). Diante disso, entendemos que a pesquisa comparada entre os diferentes sistemas do Estado-nação contribui para deflagrar as desigualdades regionais com relação ao direito à educação. Todavia, consideramos essas distinçóes e semelhanças entre os sistemas o produto de um processo histórico, em que o contexto específico é, de certa forma, a manifestação contraditória e peculiar do contexto geral. Conforme Alves (2006):

[...] as categorias científicas mais gerais não podem ser exclusivas e nem excludentes no processo de investigação científica, pois o singular não é uma forma de realização reflexa do universal. Mesmo sendo a única forma sob a qual o universal se realiza, "o singular é, sempre, uma forma de realizaçáo peculiar do universal”. Por conter, inclusive, aspectos que fogem às formas mais desenvolvidas do universal, o singular exige, também, a construção de categorias científicas apropriadas à sua apreensão plena (ALVES, 2006, p.13).

${ }^{5}$ Para aprofundar essa concepção, sugerimos a leitura do Parecer CNE/CEB n. 30/2000. 
A análise com foco na tessitura de uma política intergovernamental é feita por meio da abordagem cognitiva de políticas públicas, proposta por Muller e Surel (2002). Para esses autores, as açóes de uma política pública se desencadeiam por meio de processos de tradução, em que a implementação comumente altera a formulação. Em outras palavras, na tessitura de uma política pública, está em jogo a construção coletiva de seus sentidos, de modo que as visões de mundo ou as representaçóes sociais de todos os atores ordinários estão implicadas como elemento da participação pública, não sendo possível reduzir uma política à aplicabilidade vertical de um conjunto de estratégias organizacionais.

Com relação aos indicadores estatísticos que embasam as análises do fenômeno investigado, consideramos a abordagem metodológica de natureza exploratória, reunindo dados quantitativos e qualitativos, uma vez que os indicadores numéricos nos "dizem" ou informam aspectos baseados nas perguntas que fazemos a eles, ou seja, os critérios do pesquisador participam e compóem o fenômeno, desde o recorte e seleção dos dados atésuas posteriores análises. Besson (1995) nos auxilia na compreensão das estatísticas como "verdades relativas", ao propor que pensemos que os indicadores numéricos não se reduzem à enumeração, no sentido de uma fotografia quantitativa de uma realidade que seria a mesma para todos os observadores e que, portanto, teria fim em si mesma. Ao contrário, as estatísticas são influenciadas pelas escolhas do pesquisador, pelo modo como opera a coleta e divulgação dos dados. O autor esclarece: “[...] É preciso renunciar a esta concepção das estatísticas como medida (fotografia) e admitir que estamos diante de uma observação (modelização)" (BESSON, 1995, p.26).

Em estudos anteriores, Ferraro (2012), Gonçalves, Bueno e Meletti (2013) e Meletti e Bueno (2013) vêm destacando a importância de o campo educacional apropriar-se dos indicadores sociais como ferramentas para análises qualitativas. Para Ferraro (2012), a tradição histórica, nas Ciências Humanas, de valorização dos métodos qualitativos em relação aos métodos quantitativos deve ser problematizada. $\mathrm{O}$ autor entende que os dados de uma pesquisa sugerem a indissociabilidade dos aspectos quantitativo e qualitativo, de modo que todo dado quanti é quali e vice-versa, importando à pesquisa como as diferentes competências metodológicas podem articular-se na análise de um problema social ou educacional.

Conforme Jannuzzi (2012, p.22): “[...] o indicador social é um instrumento operacional para monitoramento da realidade social, para fins de formulação e de reformulação das políticas públicas". Logo, esses indicadores são instrumentos determinantes para o monitoramento dos diferentes aspectos que envolvem a qualidade de vida da populaçáo por parte do poder público, sendo que, para a investigação acadêmica, eles contribuem à análise crítica a respeito de diferentes fenômenos sociais.

Os indicadores sociais são construídos a partir da sistematização das estatísticas públicas, por meio de diferentes instrumentos elaborados pelos órgáos públicos para coleta de dados. As estatísticas correspondem ao dado social na forma bruta (JANNUZZI, 2012). Os indicadores sociais podem contemplar diferentes temáticas de interesse público. No caso deste estudo, nossa atenção está voltada aos indicadores sociais demográficos e educacionais, relativos aos instrumentos de coleta de dados oficiais brasileiros: o Censo Escolar da Educação Básica e o Censo Demográfico Brasileiro. 
Com relação ao Censo Escolar da Educação Básica, os dados que iremos apresentar foram selecionados das informaçóes divulgadas pelo Instituto Nacional de Estudos e Pesquisas Educacionais Anísio Teixeira (INEP), do Ministério da Educação,no marco temporal de 2007 a 2013 (BRASIL, 2007-2013). Construímos as análises por meio do acesso ao banco de dados de matrículas, privilegiando como variáveis ${ }^{6}$ para a investigação: modalidade de ensino (EJA comum e especial), necessidade educacional especial $(\mathrm{NEE})^{7}$, tipo de deficiência (deficiências visual, auditiva, mental/intelectual, física), dependência administrativa da escola (federal, estadual, municipal, privada) e categoria da escola privada (filantrópica, particular, confessional, comunitária)

O Censo Demográfico trata-se de um recenseamento da população brasileira que acontece em cada intervalo temporal de 10 anos, apresentando dados que auxiliam identificar as condições de vida da população brasileira. Neste estudo, estamos trabalhando com os dados decorrentes do último censo demográfico realizado no país (2010) pelo Instituto Brasileiro de Geografia e Estatística $\left(\right.$ IBGE) ${ }^{8}$. As variáveis ${ }^{9}$ selecionadas para a análise, a partir do Sistema IBGE de Recuperação Automática (SIDRA) do IBGE, correspondem ao grau de instrução escolar da totalidade da população e ao tipo de deficiência (visual, auditiva, motora, mental/ intelectual) ${ }^{10}$.

Compreendemos no olhar articulado e complementar às estatísticas educacionais e demográficas relativas aos jovens e adultos com deficiência, a possibilidade de averiguaras condições de acesso à escola da população jovem e adulta com deficiência. A análise isolada das matrículas desse público na EJA inscreve a possibilidade de constatar a manutenção, ampliação ou redução do acesso à educação formal ao longo de um percurso temporal da trajetória da política pública. Entretanto, não é suficiente para delinear a cobertura do acesso à escolarização por seus potenciais demandantes. Ao compararmos os dados educacionais com os dados demográficos, reconhecemos a garantia do direito à educação como uma temática complexa e que suscita distintas formas de abordagem dos indicadores sociais.

\footnotetext{
${ }^{6}$ As nomenclaturas das variáveis estão de acordo com o caderno de instruçốes do INEP. Disponível em: <http://portal.inep. gov.br/basica-levantamentos-microdados>. Acesso em: 22 abr. 2014. Seguem informaçóes complementares acerca das variáveis. Compóem as matrículas da deficiência visual as categorias de cegueira e baixa visão, e as matrículas de deficiência auditiva, as categorias de surdez e deficiência auditiva. No marco temporal em análise, os sujeitos identificados com deficiência mental passaram a ser nomeados pelas políticas públicas com deficiência intelectual, por isso, optamos por utilizar as duas nomenclaturas mental/intelectual. Nos anos de 2007 e 2008, o Censo Escolar da Educação Básica incluía como variável, a Síndrome de Down, portanto, no cômputo das matrículas desses anos, somamos as matrículas dos estudantes com Síndrome de Down aos estudantes com deficiência mentallintelectual. Optamos por restringir o estudo às quatro tipologias de deficiência em equiparação às variáveis abordadas pelo Censo Demográfico.

${ }^{7}$ Estudantes com deficiência, transtornos globais do desenvolvimento ou altas habilidades/superdotação (Caderno de Instruçóes, INEP).

${ }^{8}$ Disponível em:<http://7a12.ibge.gov.br/sobre-o-ibge/como-funciona-o-ibge>. Acesso em: 17 fev. 2015.

${ }^{9}$ As nomenclaturas das variáveis estão de acordo com o SIDRA (Sistema IBGE De Recuperaçăo Automática). Disponível em: <http://www.sidra.ibge.gov.br>. Acesso em: 28 jan. 2015.

${ }^{10}$ Como critérios de categorização dos sujeitos com deficiência, o SIDRA utiliza duas variáveis descritivas: "não consegue de modo algum" e "grande dificuldade".
} 


\section{QUE “DizeM" as ESTATÍsTICAS EDUCACIONAIS SOBRE OS JOVENS E ADULTOS COM DEFICIÊNCIA NA EJA}

Nas tabelas a seguir, nos dedicamos à análise das estatísticas educacionais do RS, no que concerne ao acesso dos jovens e adultos com deficiência à escolarização na EJA, nas classes do ensino comum e especial ${ }^{11}$.

A Tabela1 apresenta as matrículas totais dos jovens e adultos da EJA, as matrículas totais dos jovens e adultos com deficiência e as matrículas segundo a tipologia de deficiência, na EJA comum.

Tabela 1 - Matrículas totais de alunos na EJA comum, no estado do Rio Grande do Sul, e matrículas segundo o tipo de deficiência.

\begin{tabular}{c|c|c|c|c|c|c} 
Ano & Total & NEE & DV & DA & DF & DM \\
\hline 2007 & 186931 & 822 & 79 & 118 & 73 & 437 \\
\hline 2008 & 178407 & 1199 & 88 & 114 & 92 & 738 \\
\hline 2009 & 161370 & 1025 & 100 & 78 & 97 & 665 \\
\hline 2010 & 154725 & 1700 & 156 & 164 & 161 & 1166 \\
\hline 2011 & 151052 & 2282 & 190 & 182 & 195 & 1635 \\
\hline 2012 & 148235 & 2778 & 197 & 182 & 212 & 2073 \\
\hline 2013 & 146765 & 2762 & 198 & 186 & 210 & 2041
\end{tabular}

Fonte: (BRASIL, 2007, 2008b, 2009b, 2010, 2011a, 2012, 2013).

É notória a ampliaçãodas matrículasdos estudantes com deficiência (NEE) na EJA, em classes comuns, no período analisado, ou seja, aquelas em que a deficiência não se constitui como barreira para o acesso, sendo considerado como critério apenas o fator idade. Entendemos que a EJA comum é o espaço potente quando se refere à inclusão escolar de jovens e adultos com deficiência, uma vez que oportuniza a convivência com seus pares, permitindo que a heterogenia e as múltiplas diferenças entre os sujeitos sejam tratadas como aspectos de enriquecimento curricular.

Após esse panorama da EJA comum no Rio Grande do Sul, apresentamos a Tabela 2, que indica o cômputo total das matrículas de alunos com deficiência e por tipo de deficiência, na EJA especial, no estado gaúcho.

\footnotetext{
${ }^{11}$ Estão computados, nos dados da EJA especial, tanto as classes especiais existentes nas instituiçốes escolares de caráter exclusivamente especial (escolas especiais) como aquelas ofertadas nas instituiçóes escolares de ensino regular.
} 
Tabela 2 - Matrículas totais de alunos na EJA especial, no estado do Rio Grande do Sul, e matrículas segundo o tipo de deficiência.

\begin{tabular}{l|c|c|c|c|c}
\multicolumn{1}{c|}{ Ano } & NEE & DV & DA & DF & DM \\
\hline 2007 & 3057 & 100 & 202 & 101 & 2229 \\
\hline 2008 & 3580 & 88 & 287 & 143 & 2700 \\
\hline 2009 & 4428 & 72 & 338 & 123 & 3544 \\
\hline 2010 & 4676 & 99 & 286 & 473 & 4268 \\
\hline 2011 & 5182 & 125 & 267 & 662 & 4787 \\
\hline 2012 & 5482 & 206 & 283 & 695 & 5013 \\
\hline 2013 & 5420 & 188 & 230 & 699 & 4978
\end{tabular}

Fonte: (BRASIL, 2007, 2008b, 2009b, 2010, 2011a, 2012, 2013).

Todavia, ao compararmos os dados obtidos na Tabela 1 com os dados da Tabela 2, em que apresentamos as matrículas totais dos jovens e adultos com deficiência e segundo a tipologia da deficiência, na EJA especial,vemos que a redução das matrículas desses sujeitos na EJA comum, evidenciada na Tabela 1, pode ser considerada inexpressiva, à medida que as matrículas desse público permanecem concentradas nos espaços exclusivos da educação especial. Os dados demonstram não só a manutenção das matrículas da EJA no atendimento substitutivo como também deflagram a ampliação dessas matrículas no marco temporal analisado. Em 2013, é possível constatar um pequeno decréscimo nas matrículas da EJA especial, porém, consideramos esse decréscimo sem relevância como indício das açôes da Política de Educação Especial na perspectiva da Educação Inclusiva, uma vez que essa diminuição numérica das matrículas nesse ano (2013) também aparece refletida nos dados da EJA comum e nos dados totais de matrículas da EJA.

Quando se analisam as matrículas por tipologia, percebemos que apenas com relação à deficiência visual, os dados de acesso à EJA comum se sobrepóem aos dados da EJA especial. Com as demais deficiências, prevalecem as matrículas nas classes especiais de EJA, destacando-se a deficiência mental/intelectual pela volumosa quantidade de matrículas.

Esse panorama nos auxilia a compreender que prevalece o discurso clínico da "gravidade" da deficiência, como aspecto que inscreve o acesso dos jovens e adultos com deficiência aos espaços escolares da EJA. O jovem e adulto com cegueira e baixa visão continua sendo narrado como o sujeito mais "educável" perante os sujeitos com deficiência intelectual, sendo esses últimos tratados como "difíceis" de serem escolarizados. Também consideramos aspecto merecedor de atenção a quantidade expressiva de matrículas de sujeitos com deficiência física na EJA especial. A ausência de mobilidade ou a mobilidade reduzida nos parece um argumento muito "fraco" para retenção desses sujeitos nas classes especiais, uma vez que hoje a escola conta com a contribuição significativa da área da Tecnologia Assistiva ${ }^{12}$, trazendo, por meio de diversas ferramentas, a possibilidade efetiva de inclusão escolar desse público.

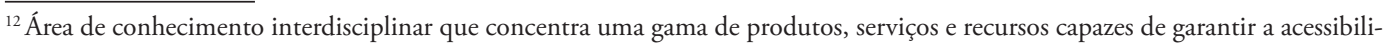
dade com autonomia e independência das pessoas com deficiência. Essa área tem sido amplamente reconhecida nas pesquisas, bem como, citada nos documentos da Política de Educação Especial na perspectiva da Educação Inclusiva como de suma importância para os processos escolares inclusivos. 
Ao confrontarmos os dados das matrículas dos jovens e adultos com deficiência nas classes comuns e especiais da EJA, no RS,com asestatísticas educacionais nacionais (BRASIL, 2013), percebemos que o estado do RS não tem acompanhado a flutuação de matrículas manifestada nacionalmente, conforme demonstra o Gráfico 1.

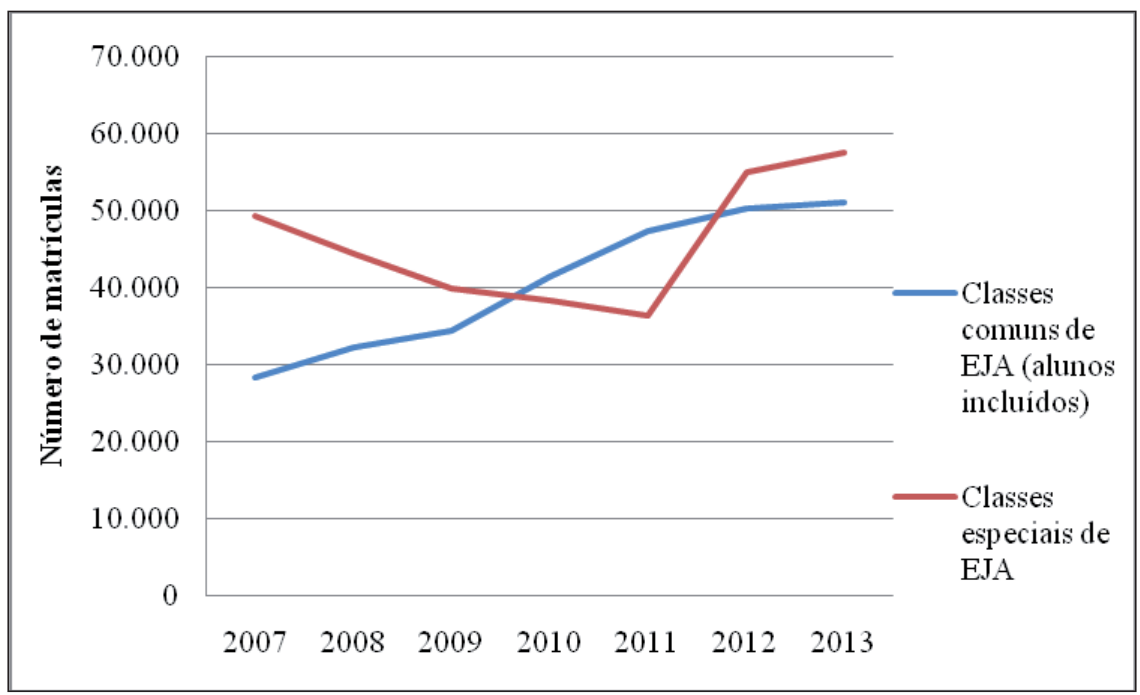

Gráfico 1 - Cômputo das matrículas de jovens e adultos com deficiência na EJA comum e especial no território nacional.

Fonte: (BRASIL, 2014b).

Legenda: EJA - Educação de Jovens e Adultos.

No intervalo de 2007 a 2010, os dados nacionais registram um declínio das matrículas de alunos com deficiência na EJA especial, apesar de serem elas predominantes em relação à EJA comum, conforme Gonçalves, Bueno e Meletti (2013). Ao atualizarmos os dados referentes ao período de 2011-2013, verificamos uma alteração significativa nesse registro. No ano de 2011, as estatísticas educacionais brasileiras demonstram a mudança na curva das matrículas dos jovens e adultos com deficiência,as quaispassam a ser superiores na EJA comum. Em 2012 e 2013, registra-se novamente uma modificação na tendência das matrículas, que se ampliam na EJA especial, superando numericamente as matrículas na EJA comum (BRASIL, 2014b).

Ao cotejar as matrículas de alunos com deficiência na EJA comum dos os anos de 2013 a 2007, verificamos uma ampliação de 80,5\% das matrículas no período. Em contrapartida, as matrículas desse mesmo público na EJA especial registram um declínio de 26, 2\% até o ano de 2011. A trajetória dessas últimas matrículas se inverte a partir de 2012, com uma ampliação de 34\% e, em 2013, apresenta outro aumento (4,5\%), mantendo a tendência histórica de supremacia das matrículas dos estudantes com deficiência na modalidade EJA de atendimento escolar exclusivamente da Educação Especial. Apenas em 2010, esse movimento histórico foi subvertido, sendo maior o número de matrículas desses estudantes nas EJAs ofertadas em escolas comuns. Nesse aspecto, a linha das matrículas dos jovens e adultos com deficiência na EJA especial no RS segue em progressão de modo inflexível, escrevendo uma trajetória paralela e paradoxal à inclusão escolar manifesta nas demais etapas de ensino e modalidades 
que compóem a Educação Básica no estado. O Gráfico 2, a seguir, apresenta a distribuição das matrículas nas classes de EJA (comum e especial) no RS de acordo com a dependência administrativa (privada e pública).

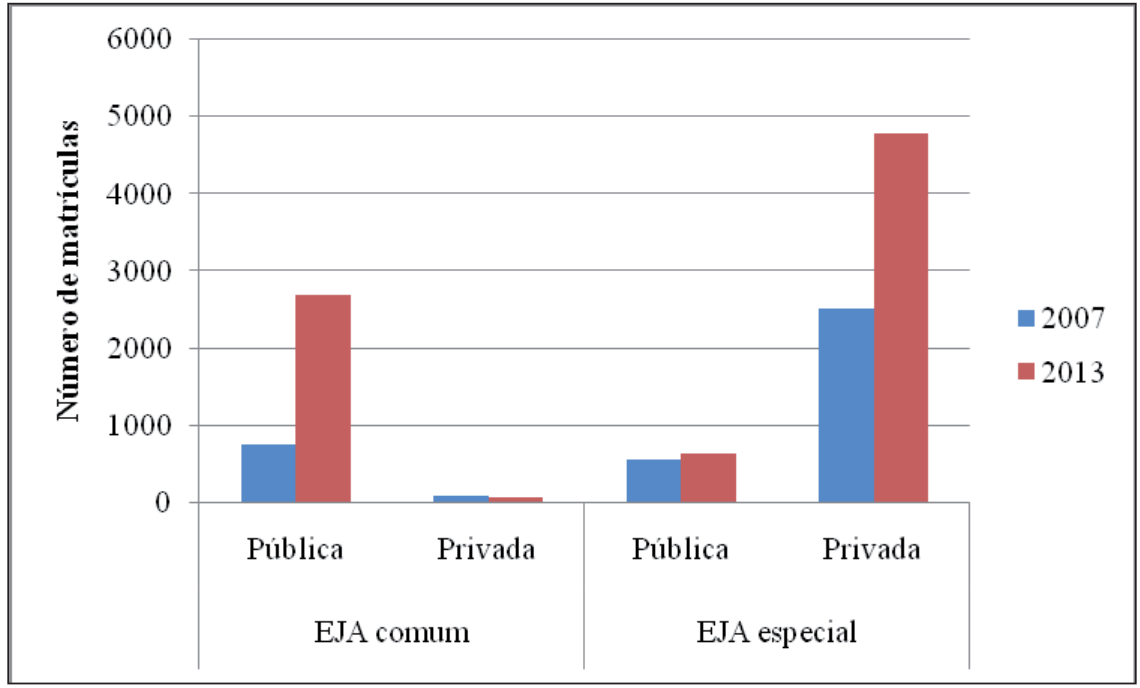

Gráfico 2 - Matrículas de alunos com NEE na EJA comum e especial segundo a dependência administrativa da escola no estado do Rio Grande do Sul.

Fonte: (BRASIL, 2007, 2013).

Legenda: EJA - Educação de Jovens e Adultos.

Os dados indicam que a tendência das matrículas de alunos com deficiênciana EJA comum, no estado do RS, é de ampliação (260, 2\%) em instâncias públicas, sobretudo em esferas municipais, o que pode estar indicando a manutenção desses alunos na etapa do ensino fundamental, cujo atendimento vem sendo realizado, prioritariamente, pelos municípios. Estes têm assumido tal responsabilidade por força da regulamentação das competências e atribuições dos entes federados com relação à organização nacional da educação (BRASIL, 1996), reforçada por mecanismos políticos federais, tais como oFundo Nacional de Manutenção e Desenvolvimento do Ensino Fundamental e de Valorização do Magistério (FUNDEF). No que se refere à ação da esfera pública, a marginalização da EJA aparece de modo substancial nas políticas de financiamento. Com a implementação do FUNDEF, em 1998, a divisão de responsabilidades sobre a educação proposta pelo Fundo, pouco contribuiu para aumentar a eficiência da gestão do sistema e, menos ainda, para a qualidade do ensino público (PINTO, 2007). A pior implicação do FUNDEF durante sua vigência de 1998 a 2006 foi “[...] desconsiderar as matrículas da EJA no repasse de verbas, poiso Fundef marginalizou ainda mais a educação oferecida à população jovem e adulta, mantendo o descaso com que essa modalidade de ensino tem sido tratada pelo poder público" (CARVALHO, 2014, p.2).

Em 2007, o FUNDEF foi substituídopelo Fundo de Manutenção e Desenvolvimento da Educação Básica e de Valorização dos Profissionais da Educação (FUNDEB), com vigência até 2020. O FUNDEB passou a financiar todas as matrículas da educação básica, desde a cre- 
che até o ensino médio, elevando a participação de recursos da União. Porém,no que se refere à EJA, dois pontos foram questionados por Carvalho (2014):

1) a limitação de um percentual máximo de quinze por cento dos recursos do Fundeb para essa modalidade de ensino; e 2) a fixação do fator de ponderaçáa ${ }^{13}$ atribuído à EJA de 0,7 do valor de referência estabelecido às séries iniciais do ensino fundamental "regular" urbano no ano de implantação do Fundeb, menor dentre todas as etapas e modalidades da educação básica (CARVALHO, 2014, p.2).

O fator de ponderação da EJA pelo FUNDEB foi de 0,7, para 2007, com base no 1,0 do ensino fundamental-regular séries iniciais, indicando que a educaçáo para as pessoas jovens e adultas ainda é tratada de forma indistinta (CARVALHO, 2014). Nos últimos 40 anos, o ensino público para EJA pode ser considerado como um serviço desconcentrado, pois, mesmo ofertando escola predominantemente nos municípios e organizaçôes civis, "a política educacional e o desenho dos programas eram definidos no âmbito federal e desenvolvidos em regime de co-financiamento" (DI PIERRO, 2001, p.323).

As dificuldades históricas do Estado em consolidar uma política pública para a EJA reforçam-se ao tratar-se do público da Educação Especial, o que é possível apreciar por meio dos dados estatísticos, com relação à concentração das classes de EJA Especiais na dependência administrativa privada. Ao analisarmos os microdados do ano de 2013, verificamos que $88,3 \%$ das matrículas de alunos com deficiênciana EJA Especial no estado do RS condizem à esfera privada. Em números absolutos, isso significa 4.788 matrículas na EJA especial, na esfera privada, ao passo que 218 matrículas estão na esfera estadual, 414 matrículas na esfera municipal e nenhuma matrícula na esfera federal (BRASIL, 2013). De 2007 a 2013, as matrículas desse segmento na instância privada ampliaram-se em 90,5\% (de 2.514 para 4.788 matrículas).

Ao cotejar as matrículas de alunos com deficiência na EJA comum com a especial, percebemos a predominância da EJA especial no intervalo investigado, sendo que,em 2013, 58,5\% das matrículas totais de NEE da EJA do estado do Rio Grande do Sul estão sob o domínio do poder privado. A partir desse dado, consideramos relevante verificar a categoria de escola privada que financia a EJA especial, conforme demonstra o Gráfico 3.

\footnotetext{
${ }^{13}$ Os fatores são utilizados na ponderação do número de alunos, para fins de distribuição dos recursos do Fundo, ou seja, representam as diferenças de valor por aluno/ano utilizadas para os dezenove segmentos em que a educação básica foi dividida, para fins de operacionalização do Fundeb. Disponível em: <http://www.fnde.gov.br>. Acesso em: 6 set. 2014.
} 


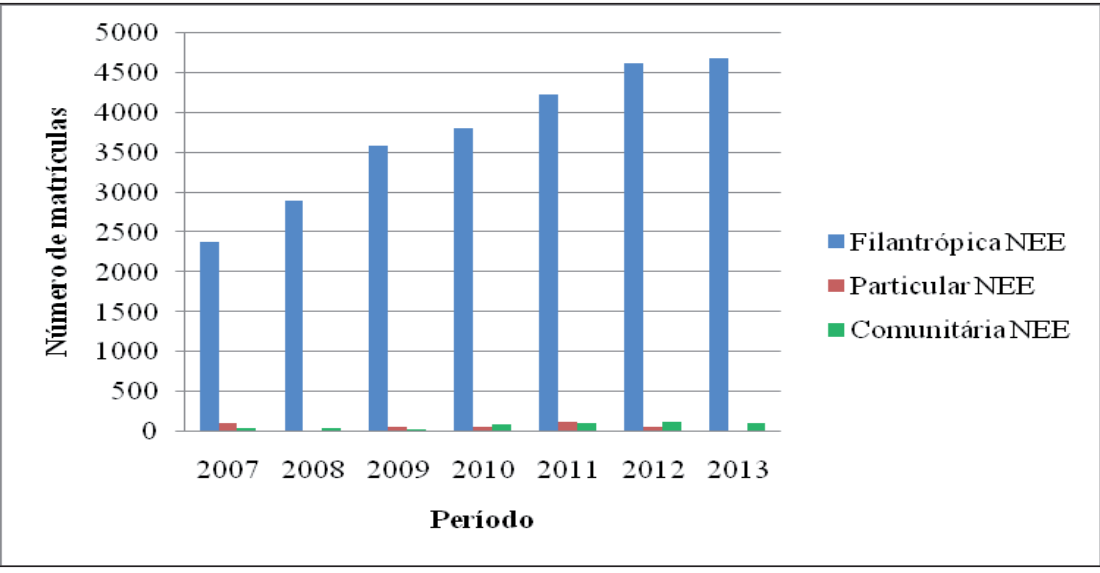

Gráfico 3 - Matrículas de alunos com NEE na EJA especial segundo a categoria da escola privada no estado do Rio Grande do Sul.

Fonte: (BRASIL, 2007, 2008b, 2009b, 2010, 2011a, 2012,2013).

Legenda: NEE - Necessidades Educacionais Especiais.

Segundo os microdados do INEP, há quatro categorias de escolas privadas (filantrópica, particular, comunitária e confessional). No período analisado, a categoria confessional não apresentou financiamento à EJA especial no estado do Rio Grande do Sul.

Baseando-se no Gráfico 3, fica evidente a predominância da filantropia na EJA especial. Essa tendência é decorrente da história da Educação Especial, em que assumiu um caráter assistencialista na política educacional brasileira, sendo visível o fortalecimento de instituiçóes particulares, filantrópicas e assistencialistas, reforçando o discurso da solidariedade para os excluídos e da responsabilidade social para com as pessoas com algum tipo de deficiência. Conforme Viegas e Bassi (2009):

[...] o financiamento, já insuficiente para a área da Educação Especial, é transferido para as instituiçóes sociais, que ampliam seus recursos com as doaçôes da sociedade civil e verbas privadas. Nem sempre, no entanto, como mostra a realidade das instituiçóes que atendem crianças e jovens com deficiência e em idade escolar, há uma preocupação ou mesmo uma proposta educacional por parte dessas instituiçóes, que, muitas vezes, arcam com os cuidados para com a higiene e segurança destas pessoas, sem qualquer conotação educativa formal (VIEGAS; BASSI, 2009, p.58).

Em 2011, o Decreto Federal 7.611/2011 (BRASIL, 2011b), que regulamenta a Educação Especial e o Atendimento Educacional Especializado, reforça o que já existia enquanto política pública no país: a transferência de recursos financeiros para as instituiçóes filantrópicas. Lê-se, em seu artigo 14:

Admitir-se-á, para efeito da distribuição dos recursos do FUNDEB, o cômputo das matrículas efetivadas na educação especial oferecida por instituiçôes comunitárias, confessionais ou filantrópicas sem fins lucrativos, com atuação exclusiva na educação especial, conveniadas com o Poder Executivo competente (BRASIL, 2011b, art.14). 
Ao cotejar o ano de 2013 com o de 2007, verificamos uma ampliação de 2.379 para 4.679 matrículas. Em porcentagens, isso representa a ampliação de 96,7\% das matrículas da filantropia, o que significa que essa categoria de escola privada continua com força no estado, quando se refere ao público jovem e adulto com NEE. O número de 168 estabelecimentos $^{14}$ exclusivos da Educação Especial da esfera privada, em atividade no RS, também reforça essa estatística.

Ao compararmos as matrículas desses alunos por tipologia de deficiência, percebemos que a deficiência mental predomina na EJA especial em instituiçóes filantrópicas, correspondendo, em média, no período analisado, a 84,7\% das matrículas de alunos com NEE.

\section{QUE “DIZEM” AS ESTATÍSTICAS DEMOGRÁFICAS SOBRE A ESCOLARIZAÇÃO DOS JOVENS E ADULTOS COM DEFICIÊNCIA?}

O Censo Demográfico de 2010 (IBGE) esclarece que somos 190.755 .799 brasileiros. Ao tratar das pessoas com deficiência permanente (visual, auditiva, motora, mental/ intelectual) ${ }^{15}$, o IBGE (2010) aponta que, no Brasil, há um total de 15.750.969 (8,25\%) indivíduos.

Ao analisarmos as regióes, segundo o número de pessoas com deficiência, baseando- nos no total da população, verificamos que a região Nordeste apresenta o maior percentual de pessoas com deficiência (9,5\%), seguida pela região Sul (8,2\%), o que, em números absolutos, representa, respectivamente, 5.041.537 e 2.246.881 pessoas com deficiência. A regiáo Sudeste figura com $7,8 \%$ de pessoas com deficiência, proporcionalmente à população total da regiấo. Já a região Norte conta com 7,5\% da população com deficiência e aCentro-Oeste com 7,3\% (BRASIL, 2010).

Outro dado apresentado pelo IBGE (BRASIL, 2010) é que o Brasil ainda possui um alto índice de pessoas sem instrução ou com o Ensino Fundamental incompleto. Em nosso país, há 13.660.168 pessoas analfabetas com 15 anos ou mais. Dentre as pessoas com deficiência, nessa faixa etária, 4.645.145 não são alfabetizadas (BRASIL, 2010).

Na região Sul, foco do nosso estudo, 496.605 pessoas com deficiência, com 15 anos ou mais de idade, são consideradas analfabetas, o que representa $10,7 \%$ da população brasileira com deficiência e analfabeta, nessa faixa etária. Ao analisar o estado do Rio Grande do Sul, verificamos que 187.428 pessoas com deficiência, com 15 anos ou mais, são analfabetas, o que representa $37,7 \%$ da população do Sul com deficiência e analfabeta, com 15 anos ou mais.

\footnotetext{
${ }^{14}$ Disponível em:<http://www.dataescolabrasil.inep.gov.br/>. Acesso em: 21 abr. 2015.

${ }^{15}$ Conforme o IBGE, com a autodeclaração, as pessoas afirmavam ter as seguintes características: não conseguem de modo algum ou têm grande dificuldade na capacidade visual, auditiva, motora, mental/ intelectual.
} 
Tabela 3 - Número de pessoas com deficiência, com 15 anos ou mais, analfabetas, no estado do Rio Grande do Sul.

\begin{tabular}{l|c|c|c|c|c}
\multirow{2}{*}{ Idade } & Total de pessoas com & \multicolumn{4}{|c}{ Tipos de deficiência } \\
\cline { 5 - 6 } & deficiência & $\begin{array}{c}\text { Deficiência } \\
\text { visual }\end{array}$ & $\begin{array}{c}\text { Deficiênciaau- } \\
\text { ditiva }\end{array}$ & $\begin{array}{c}\text { Deficiência } \\
\text { motora }\end{array}$ & $\begin{array}{c}\text { Mental/ Inte- } \\
\text { lectual }\end{array}$ \\
\hline 15 a 19 & 7430 & 462 & 422 & 1457 & 5089 \\
\hline 20 a 24 & 6718 & 631 & 273 & 1110 & 4704 \\
\hline 25 a 29 & 6751 & 615 & 401 & 1220 & 4515 \\
\hline 30 a 34 & 6958 & 710 & 655 & 1173 & 4420 \\
\hline 35 a 39 & 6844 & 730 & 814 & 977 & 4323 \\
\hline 40 a 44 & 8443 & 1626 & 976 & 1442 & 4399 \\
\hline 45 a 49 & 9894 & 2513 & 935 & 2238 & 4208 \\
\hline $\begin{array}{l}50 \text { anos ou } \\
\text { mais }\end{array}$ & 134390 & 42878 & 22795 & 47670 & 21047
\end{tabular}

Fonte: (BRASIL, 2010).

Ao somarmos as estatísticas demográficas relativas às faixas etárias de 15 a 29 anos, marco temporal reconhecido culturalmente como juventude, obtemos um total de 20.899 sujeitos sem instrução escolar. Ao compararmos esse número com o total de sujeitos com deficiência que têm acesso à EJA, na mesma época de coleta dos dados demográficos (2010), constatamos 4.676 matrículas na EJA especial e 1.700 matrículas na EJA comum, totalizando 8.376 matrículas. Portanto, as vagas existentes sãobem inferiores ao número de jovens com deficiência que poderiam ser potenciais demandantes da EJA. A situação é ainda mais gravequando contabilizadas todas as faixas etárias categorizadas no censo demográfico brasileiro.

\section{Consideraçóes finais}

No estado do Rio Grande do Sul, os dados do censo escolar apontam para uma ampliação das matrículas dos alunos com deficiência nas classes comuns de EJA. Paralelamente, também sinalizam a ampliação dessas matrículas, nas classes especiais de EJA, em maiores números absolutos, em relação à ampliação nas classes comuns. Essa tendência de ampliação da EJA especial também é manifesta nos dados dos últimos anos, em âmbito nacional.

Ao nos defrontarmos com a distribuição das matrículas da EJA especial entre as instâncias administrativas percebemos a intensidade das açóes da filantropia no estado do Rio Grande do Sul, evidenciando as tensóes da relação público/privado na garantia do direito à educação das pessoas jovens e adultas com deficiência, em tempos de inclusão e de democratização do direito à educação.

A Nota Técnica n. 62/2011 SECADI/MEC em explicação ao Decreto Federal $7611 / 2011$ (BRASIL, 2011c) previa que o apoio financeiro às instituiçóes especializadas jus- 
tificava-se essencialmente pelo atendimento às pessoas que não estão matriculadas no ensino regular e que se encontram fora da faixa etária de escolarização obrigatória, em razão de um processo histórico de exclusão escolar. Embora o contexto nos pareça justificável, o que observamos nesses últimos anos nos sugere uma "corrida" das instituições especializadas privadas em busca desse público, como forma de garantir a sua manutenção. Por outro lado, essa abertura crescente para a atuação das instituições especializadas privadas no RS aponta para uma fragilização do estado na garantia da cobertura do direito à educaçáo desse público.

Ocenso demográfico de 2010 revelou que 37,7\% das pessoas com deficiência, com 15 anos ou mais, são analfabetas no RS, sinalizandoque muitas pessoas ainda estão excluídas da escola, sem apropriação dos conteúdos considerados necessários para o exercício da cidadania. Essa realidade também carece de novosestudos para verificar se essa condição de exclusão pela deficiência está associada à distribuição de renda, dentre outros fatores sociais tão desiguais em nosso país.

Assim, os dados nos mostram que grande parte desse público continua excluído da escola, sem acesso à escolarização ou com trajetórias escolares exclusivas nos espaços especializados. Mediante os argumentos analisados e as novas questóes elencadas, compreendemos que as ações políticas intergovernamentais de Educação Especial em foco no estado do RS e no país, no que se refere aos jovens e adultos com deficiência,têm se mostrado em descompasso em relação à tendência de intensificação da diretriz da inclusão escolar, expressa no cômputo das matrículas gerais da Educação Básica, em ambos os contextos. Desse modo, é salutar que se reconheçam as especificidades das trajetórias humanas dos sujeitos jovens e adultos com deficiência no processo de elaboração e tradução das políticas públicas.

\section{REFERÊNCIAS}

ALVES, G. L. A produção da escola pública contemporânea. 4.ed. Campinas: Autores Associados, 2006.

BAPTISTA, C.R. A ação pedagógica e a educação especial: a sala de recursos como prioridade na oferta de serviços especializados. Revista Brasileira de Educação Especial, Marília, v.17, n.esp., p.59-76,2011.

BAPTISTA, C. R.; HAAS, C.; FREITAS, C.R. Contextos de convergência: a Educação Especial, as políticas públicas e os processos escolares inclusivos. In: BOLZAN, D. P. (Org.). Encontro Internacional de Investigadores de Políticas Educativas. Santa Maria: Universidade Federal de Santa Maria; Associación de Universidades Grupo Montevidéo, 2014. p.145-149.

BESSON, J.L. As estatísticas: verdadeiras ou falas? In: BESSON, J.L. (Org.). A ilusão das estatísticas. Tradução de Emir Sader. São Paulo: UNESP, 1995. p.25-67.

BRASIL. Lei n ${ }^{\circ}$. 9.394, de 20 de dezembro de 1996. Estabelece as diretrizes e bases da educação nacional. 1996. Disponível em: <http://portal.mec.gov.br/seesp/ arquivos/pdf/ lei9394_ldbn1.pdf>. Acesso em: 13dez. 2015.

BRASIL. Ministério da Educação. Instituto Nacional de Estudos e Pesquisas Educacionais Anísio Teixeira - INEP. Censo Escolar da Educação Básica - 2007. Brasília, DF, 2007. Disponível em: <http:// www.inep.gov.br/basica/levantamentos/microdados.asp>. Acesso em: 12 abr. 2015.

BRASIL. Ministério da Educação. Secretaria de Educação Especial. Política nacional de educação especial na perspectiva da educação inclusiva. Brasília, DF: 2008a. 
BRASIL. Ministério da Educação. Instituto Nacional de Estudos e Pesquisas Educacionais Anísio Teixeira - INEP. CensoEscolar da Educação Básica - 2008. Brasília, DF, 2008b. Disponível em: <http:// www.inep.gov.br/basica/levantamentos/microdados.asp>. Acesso em: 12 abr. 2015.

BRASIL. Casa Civil. Emenda Constitucional n. 59, de 11 de novembro de 2009. Brasília, DF, 2009a.

BRASIL. Ministério da Educação. Instituto Nacional de Estudos e Pesquisas Educacionais Anísio Teixeira - INEP. Censo Escolar da Educação Básica - 2009. Brasília, DF, 2009b. Disponível em: <http://www.inep.gov.br/basica/levantamentos/microdados.asp>. Acesso em: 13 abr. 2015.

BRASIL. Ministério da Educação. Instituto Nacional de Estudos e Pesquisas Educacionais Anísio Teixeira - INEP. Censo Escolar da Educação Básica - 2010. Brasília, DF, 2010. Disponível em: <http:// www.inep.gov.br/basica/levantamentos/microdados.asp>. Acesso em: 13 abr. 2015.

BRASIL. Ministério da Educação. Instituto Nacional de Estudos e Pesquisas Educacionais Anísio Teixeira - INEP. Censo Escolar da Educação Básica - 2011. 2011a. Disponível em: <http://www.inep. gov.br/basica/levantamentos/microdados.asp> Acesso em: 16 abr. 2015.

BRASIL. Decreto-lei n. 7611, de 17 de novembro de 2011. Dispóe sobre a educação especial, o atendimento educacional especializado e dá outras providências. Diário Oficial Brasília, 17 de novembro de 2011. Brasília, DF, 2011b.

BRASIL. Ministério da Educação. SECADI. DPEE. Nota Técnica n. 62, de 08 de dezembro de 2011. Orientaçôes aos Sistemas de Ensino sobre o Decreto no 7.611/2011. Brasília, DF, 2011c.

BRASIL. Ministério da Educação. Instituto Nacional de Estudos e Pesquisas Educacionais Anísio Teixeira - INEP. Censo Escolar da Educação Básica - 2012. Brasília, DF, 2012. Disponível em: <http:// www.inep.gov.br/basica/levantamentos/microdados.asp> Acesso em: 16 abr. 2015.

BRASIL. Ministério da Educação. Instituto Nacional de Estudos e Pesquisas Educacionais Anísio Teixeira - INEP. Censo Escolar da Educação Básica - 2013. Brasília, DF, 2013. Disponível em: <http:// www.inep.gov.br/basica/levantamentos/microdados.asp> Acesso em: 16 abr. 2015.

BRASIL. Lei Federal n. 13.005, de 25 de junho de 2014. Aprova o Plano Nacional de Educação PNE e dá outras providências. Diário Oficial Brasília, 26 de junho de 2014. Brasília, DF, 2014a.

BRASIL. Ministério da Educação. Instituto Nacional de Estudos e Pesquisas Educacionais Anísio Teixeira - INEP. Censo Escolar da Educação Básica 2013: Resumo Técnico. Brasília, DF, 2014b. Disponível em: <http://download.inep.gov.br/educacao_basica/censo_escolar/resumos_tecnicos/ resumo_tecnico_censo_educacao_basica_2013.pdf> Acesso em: 16 abr. 2015.

CARVALHO, M.P. O financiamento da EJA no Brasil: repercussóes iniciais do FUNDEB. In: CONGRESSO IBERO AMERICANO DE POLÍTICA E ADMINISTRAÇÃO DA EDUCAÇÃO, 4.,2014, Porto. Anais... Porto, 2014.

DI PIERRO, M. C. Descentralização, focalização e parceria: uma análise das tendências nas políticas públicas de educação de jovens e adultos. Educação e Pesquisa, São Paulo, p.321-338, 2001.

FERRARO, A.R. Quantidade e qualidade na pesquisa em educação, na perspectiva da dialética marxista. Pro-Posiçôes, Campinas, v.23, n.1, p.129-146, 2012. Disponível em:<http://www.scielo.br/ pdf/pp/v23n1/09.pdf. >Acesso em: 26 nov. 2014.

GONÇALVES, T.G.G.L.; BUENO, J.G.S.; MELETTI, S.M.F. Matrículas de alunos com deficiência na EJA: uma análise dos indicadores educacionais brasileiros. Revista Brasileira de Política e Administração daEducação, v.29, p.407-427, 2013. 
HAAS, C. Narrativas e percursos escolares de jovens e adultos com deficiência: "Isso me lembra uma história!". 2013. 212f. Dissertação (Mestrado), Universidade Federal do Rio Grande do Sul, Porto Alegre, 2013.

JANNUZZI, P. M. Indicadores sociais no Brasil: conceitos, fontes de dados e aplicaçóes para formulação e avaliação de políticas públicas e elaboração de estudos socioeconômicos. Campinas: Alinea, 2012.

MELETTI, S.M.F.; BUENO, J.G.S. A escolarização de alunos com deficiência intelectual: análise dos indicadores educacionais brasileiros. In: MELETTI, S.M.F.; BUENO, J.G.S. (Org.).Políticas públicas, escolarização de alunos com deficiência e a pesquisa educacional. São Paulo: Junqueira \& Marin, 2013.

MULLER, P.; SUREL, Y. A análise das politicas públicas. Pelotas: Educat, 2002.

PINTO, J.M.R. A política recente de fundos para o financiamento da educação e seus efeitos no pacto federativo.Educação e Sociedade, Campinas, v.8, n.100, p.877- 897, 2007. Disponível em: <http:// www.scielo.br/pdf/es/v28n100/a1228100.pdf> Acesso em: 4 set. 2014.

VIEGAS, L.T.; BASSI, M.E. A Educação especial no âmbito da política de fundos no financiamento da educação.Reflexão e Ação, v.17, p.54-87, 2009.

Recebido em: 21/05/2015

Reformulado em: 10/12/2015

Aprovado em: 11/12/2015 